\title{
Misterios de un rostro maya: nuevas perspectivas sobre K'inich Janaab' Pakal de Palenque
}

Kazuo Aoyama

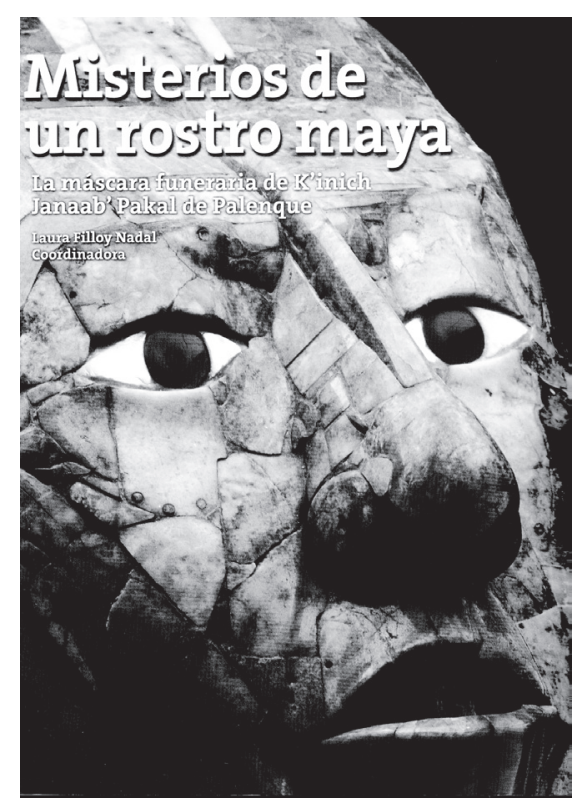

FIGURA 1. Portada del libro Misterios de un rostro maya: la máscara funeraria de K'inich Jannab' Pakal de Palenque, Laura Filloy Nadal (coord.) 2010, México, INAH.
P alenque es uno de los sitios mayas mejor conocidos incluso al otro lado del mundo, es decir, Japón, desde donde escribo. En ese contexto Misterios de un rostro maya: La máscara funeraria de K'inich Janaab' Pakal de Palenque, publicado recientemente (2010) por el Instituto Nacional de Antropología e Historia en México, dirigido tanto a académicos como al público en general, redunda en un muy atractivo y excelente libro. Éste resume los resultados de los estudios llevados a cabo por un equipo multidisciplinario sobre el gobernante — también conocido como Pakal el Grande- más importante de dicho reino maya. Las abundantes fotografías antiguas y recientes que nos ofrece, incluidas las tomadas en la década de los cincuenta en el momento del descubrimiento de este notable contexto funerario, son de gran importancia científica. Tanto las fotografías, cuya calidad es excelente, como las figuras, notablemente nítidas, ayudan al lector a entender mejor el texto. Especialmente me dejó una grata impresión el maravilloso dibujo hipotético (Filloy Nadal y Martínez del Campo, 2010: 125, figura 26) donde se señala la ubicación en que debieron haber quedado colocadas las piezas del ajuar sobre el cuerpo del soberano al ser enterrado. Por su parte, varios cuadros aportan datos numéricos presentados muy efectivamente. Considero que el cuadro 1 en particular, acerca de la cronología de la vida de K'inich Jannab' Pakal, elaborado por Simon Martin, es de gran utilidad (Martin 2010: 84-87).

Según nos narra el texto, al volver a intervenir recientemente la máscara funeraria de Pakal se realizaron trabajos de investigación que incluyeron aspectos tan diversos como la arqueología, la antropología física, la mineralogía, la epigrafía, la biología y, por supuesto, la propia restauración de la máscara. El libro deja ver la magnífica labor de conservación realizada al ajuar de Pakal por Laura Filloy Nadal y Sofía Martínez del Campo, notable por su minuciosidad y rigor. Es evidente que ésta fue una intervención que requirió paciencia y profesionalismo — realmente de calidad mundial—, que logró mantener vivas la esencia y la imagen que los artesanos mayas intentaron elaborar de su rey.

Gracias a su investigación sabemos que la máscara, principal pieza del ajuar, estuvo formada por más de 340 teselas de piedra verde, 4 aplicaciones de concha y 2 discos de obsidiana decorados con pigmento negro para simular la pupila. No es de sorprender que se haya verificado que algunas teselas 
de jade son piezas de joyería reutilizadas, pues esto era frecuente entre los mayas del Clásico. Nos reportan, además, que para dar volumen y profundidad al señorial rostro se emplearon intencionalmente jades de al menos seis tonos de verde.

Por lo que respecta al análisis, documentado en el libro, de los materiales utilizados por los lapidarios para elaborar la máscara, sus conclusiones indican que la mayoría de ellos fueron importados a través de intercambios a larga distancia, y comprueban que el jade provenía de la cuenca del río Motagua, Guatemala, mientras que la obsidiana y la concha se obtuvieron, respectivamente, de los yacimientos de El Chayal, Guatemala, y de la costa del océano Pacífico. La identificación sobre materiales y adhesivos utilizados por los mismos mayas en la reparación de la máscara da como resultado el uso de copal y cera de abejas.

En particular sobre los ojos de la máscara, las autoras proponen que su parte blanca fue hecha de concha marina tallada con materiales líticos. Según mi experiencia de muchos años de investigación sobre artefactos líticos en Copán y Aguateca (Aoyama 1999 y 2009), el análisis de microhuellas a través de microscopios de gran alcance (en concreto el metalográfico de 50-500X con accesorio de luz incidente) permite concluir que la concha marina fue trabajada en esos sitios por los mayas del Clásico, específicamente con lascas de sílex y algunas navajas gruesas de obsidiana, por lo que sugeriría a las autoras la utilización, en futuros análisis, de este mismo tipo de microscopio para poder estudiar en detalle huellas de uso.
El libro aporta un pormenorizado microanálisis de los materiales con los que fue cubierta, presumiblemente durante su ritual funerario, la osamenta del rey encontrada en el sarcófago, que detectó al menos seis estratos superpuestos de distintos materiales: resina natural, cinabrio, chapopote, cinabrio mezclado con hematita, y hematita mezclada con chapopote.

Como los autores de Misterios de un rostro maya subrayan, más de medio siglo ha pasado desde que el gran arqueólogo Alberto Ruz Lhuiller (1906-1979) hiciera, en 1952, el tal vez mayor descubrimento de entre los restos de la cultura maya: la tumba de Pakal el Grande. Si bien hoy en día éste es uno de sus gobernantes más concienzudamente investigados y, a través de estudios como los que aquí se reseñan, conocemos muchos más detalles sobre él, algunos aspectos a su respecto siguen generando grandes debates. Entre ellos está, por ejemplo, el de la edad del personaje enterrado. Los antropólogos físicos Arturo Romano Pacheco y Josefina Bautista Martínez siguen sosteniendo en el capítulo que escriben que se trata de un individuo de entre 40 y 50 años (Romano y Bautista 2010: 102), mientras que Stout y Streeter (2006) proponen, con base en lo documentado por la epigrafía y en el análisis histomorfométrico de hueso cortical de la costilla de Janaab' Pakal, que el soberano sobrevivió alrededor de 80 años. Asimismo, varios especialistas interpretan la iconografía de la famosa tapa de su sarcófago como representación del rey en el preciso momento en que, al morir, desciende a la tierra, en tanto que otros muchos consideran, por el contrario, que aparece emergiendo de ella (Stuart y Stuart 2010: 52).

En mi opinión, una pregunta relevante que estamos obligados a hacernos después de leer este espléndido libro es quiénes fueron los artesanos mayas de Palenque responsables de la elaboración de los magníficos objetos encontrados junto al cuerpo del rey. Si podemos aprender de lo estudiado en Aguateca (Guatemala), otra ciudad maya del Clásico que tuvo que ser súbitamente abandonada por sus ocupantes (alrededor del $810 \mathrm{dC}$ ), los datos líticos sugieren que una porción significativa de las elites mayas (tanto hombres como mujeres), incluidos cortesanos de alto rango y aun la propia familia real, se dedicó a la creación artística y a la producción artesanal altamente especializada, trabajando frecuentemente en dos contextos: tanto producción independiente como dependiente (Aoyama 2009).

Esperamos que nuevas excavaciones y estudios como los que conforman el libro que aquí nos ocupa puedan darnos en un futuro próximo más luz sobre la corte real de Palenque y sobre quienes en ella participaban en la producción artesanal y artística. Si, como resaltan David y George Stuart en su contribución (Stuart y Stuart 2010: 47), hasta la fecha se ha explorado tan sólo $2 \%$, aproximadamente, de todo ese famoso sitio, es evidente que queda mucho trabajo por hacer y aún nos esperan múltiples y maravillosos hallazgos, lo que no solamente será de gran interés para México sino también para el resto del mundo. 


\section{Referencias}

Aoyama, Kazuo

1999 Ancient Maya State, Urbanism, Exchange, and Craft Specialization: Chipped Stone Evidence from the Copán Valley and the La Entrada Region, Honduras, Pittsburgh, University of Pittsburgh, Memoirs in Latin American Archaeology 12.

2005 Kodai Maya (Los antiguos mayas), Kyoto, Kyoto University Press.

2009 Elite Craft Producers, Artists, and Warriors at Aguateca: Lithic Analysis (Monographs of the Aguateca Archaeological Project First Phase, vol. 2), Salt Lake City, University of Utah Press.

Filloy Nadal, Laura (coord.)

2010 Misterios de un rostro maya: la máscara funeraria de K'inich Janaab' Pakal de Palenque, México, INAH.

Filloy Nadal, Laura y Sofía Martínez del Campo Lanz

2010 "Rostro eterno de K' inich Jannab'

Pakal. La máscara funeraria", en Laura

Filloy Nadal (coord.), Misterios de un rostro maya: la máscara funeraria de K'inich Janaab', México, INAH,109-129. Martin, Simon

2010 "Biografía de K'inich Janaab' Pakal", en Laura Filloy Nadal (coord.), Misterios de un rostro maya: la máscara funeraria de K'inich Janaab Pakal de Palenque, México, INAH, 71-89.

Romano Pacheco, Arturo y Josefina Bautista Martínez

2010 “Estudios antropométricos de los restos esqueléticos de K'inich Janaab' Pakal y de sus imágenes en estuco", en
Laura Filloy Nadal (coord.), Misterios de un rostro maya: la máscara funeraria de K'inich Janaab' Pakal de Palenque, México, INAH, 99-105.

Stout, Sam D. y Margaret Streeter 2006 "A histomorphometric analysis of the cortical bone of Janaab' Pakal's rib", en Vera Tiesler y Andrea Cucina (eds.), Janaab' Pakal of Palenque: Reconstructing the Life and Death of a Maya Ruler, Tucson, University of Arizona Press.

Stuart, David y George Stuart

2010 "Arqueología e interpretación del Templo de las Inscripciones de Palenque, 1922-2005", en Laura Filloy Nadal (coord.), Misterios de un rostro maya: la máscara funeraria de K'inich Janaab' Pakal de Palenque, México, INAH, 43-67. 